\title{
RHEALITY: Recurrence of HEr2 + pAtients: evaluation of Long term outcome In patients receiving trastuzumab TherapY
}

\section{CURRENT STATUS: POSTED}

Research Square

Mahasti Saghatchian

Hopital Americain de Paris

Elsa Curtit

Centre Hospitalier Universitaire de Besancon

David Coeffic

Polyclinique Courlancy

Alain Flinois

Kantar

\ alain.flinois@kantar.comCorresponding Author

ORCiD: https://orcid.org/0000-0001-9842-1046

Christelle Levy

Centre Francois Baclesse Centre de Lutte Contre le Cancer

DOI:

$10.21203 / \mathrm{rs} .2 .14778 / \mathrm{v} 1$

SUBJECT AREAS

Cancer Biology Oncology

KEYWORDS

early breast cancer, adjuvant trastuzumab, cohort study, disease recurrence 
Abstract

Background Despite improved prognosis of HER2 + eBC since the introduction of trastuzumab in the adjuvant setting in 2006, disease recurrences still occur in some patients after a few years. We aimed to describe in real life the long-term follow-up to assess disease-free and metastasis-free survival of patients with HER2 + eBC treated with adjuvant trastuzumab.

Methods This was a multicenter, retrospective, cohort study assessing HER2 + eBC patients diagnosed between 2009 and 2010 and treated with adjuvant trastuzumab. Data were collected from patient's medical charts. Disease-free survival (DFS), and metastatic-free survival (MFS) were evaluated in the overall population and within subgroups according to hormonal and nodal status.

Results In the overall population $(n=2,513)$ at 7 years, the DFS rate was $75.8 \%[95 \% \mathrm{Cl} 74.0 \%-77.6 \%]$, and the MFS rate was $84.1 \%$ [82.5\%-85.6\%]. According to hormonal status, the 7-year DFS rate was significantly higher for HR+ than for HR-patients [80.0\% vs . 68.6\%; $p<0.001$ ], and the 7-year MFS rate $[87.9 \%$ for HR+ vs . $77.5 \% \mathrm{HR}-$ ]. According to nodal status, the 7-year DFS rate was significantly higher for $\mathrm{N}$ - than for $\mathrm{N}+$ patients [86.7\% vs . 66.4\%; $\mathrm{p}<0.001$ ], and the 7 -year MFS rate [94.7\% for $\mathrm{N}-$ vs $.74 .9 \%$ for $\mathrm{N}+]$.

Conclusions Despite introduction of adjuvant trastuzumab, prognosis of HER2 + eBC is still a matter above all in subgroups associated with a higher risk of disease recurrence. Our real-world study pointed out a particularly aggressive profile of $\mathrm{N}+$ and $\mathrm{HR}$ - subgroups and the need for more efficient approaches for these particular group of patients.

Full Text

Due to technical limitations, full-text HTML conversion of this manuscript could not be completed. However, the manuscript can be downloaded and accessed as a PDF.

Figures 


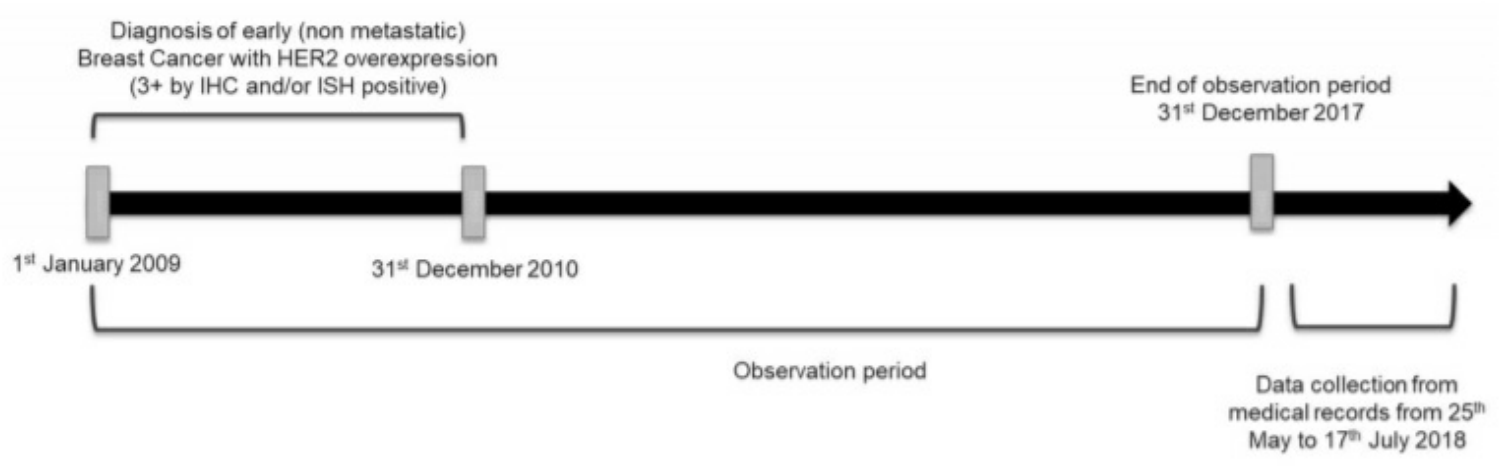

Figure 1

Study design 
A

Hormonal status at diagnosis $=\mathrm{HR}-=\mathrm{HR}+$

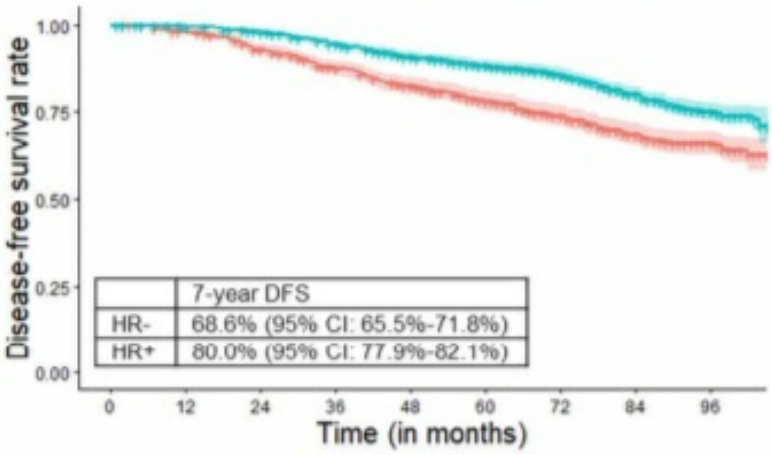

Number at risk
B

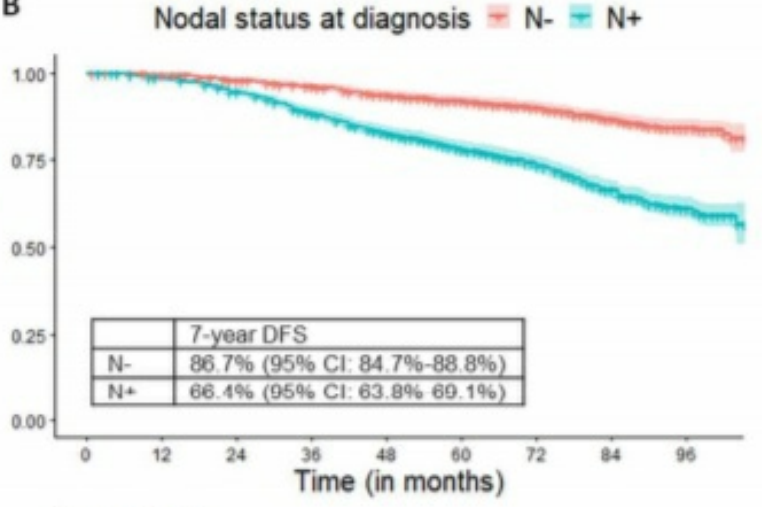

Number at risk

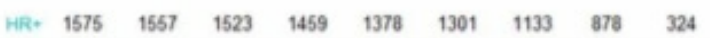

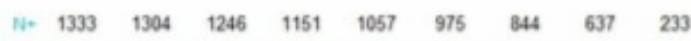

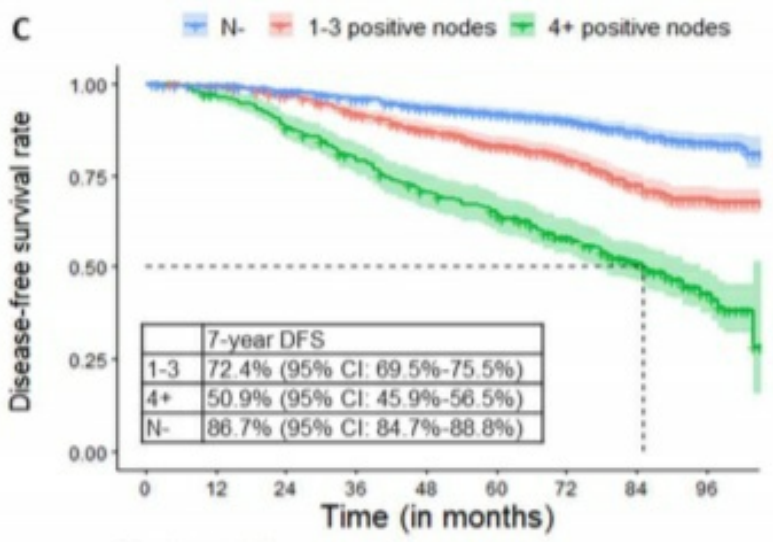

D

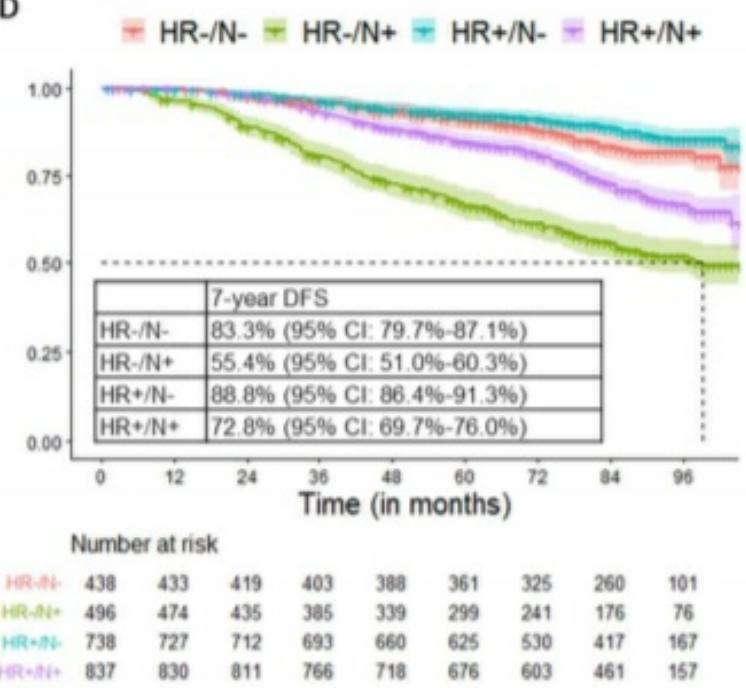

Figure 2

Kaplan-Meier disease-free survival curves for subgroups 
A

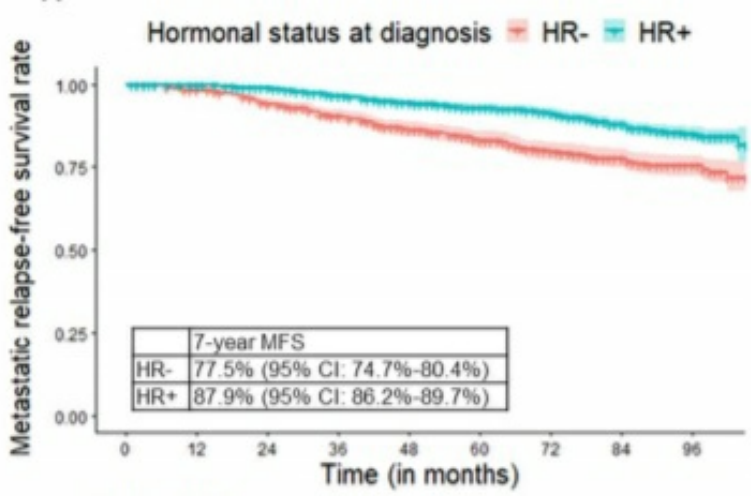

Number at risk

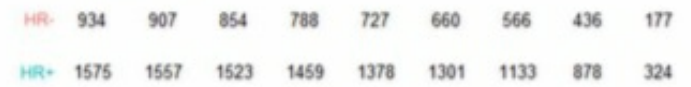

c

$+\mathrm{N} .+1.3$ positive nodes $\div 4+$ positive nodes

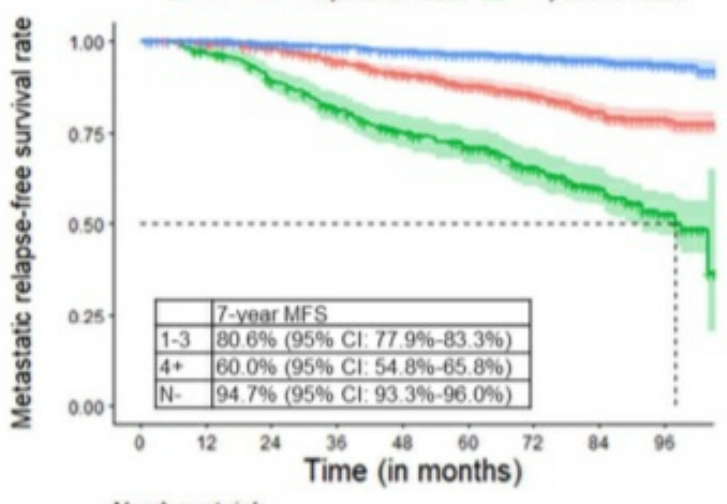

Number at risk

$\begin{array}{llllllllll}\text { 1.3 posatwe nodes } & 964 & 949 & 921 & 863 & 807 & 746 & 654 & 495 & 182\end{array}$

$\begin{array}{llllllllll}\text { 4* positive nodes } & 369 & 355 & 325 & 288 & 250 & 229 & 190 & 142 & 51\end{array}$

N. $\begin{array}{lllllllll}1176 & 1160 & 1131 & 1096 & 1048 & 986 & 855 & 677 & 268\end{array}$
B

Nodal status at diagnosis $\div \mathrm{N}-\div \mathrm{N}+$

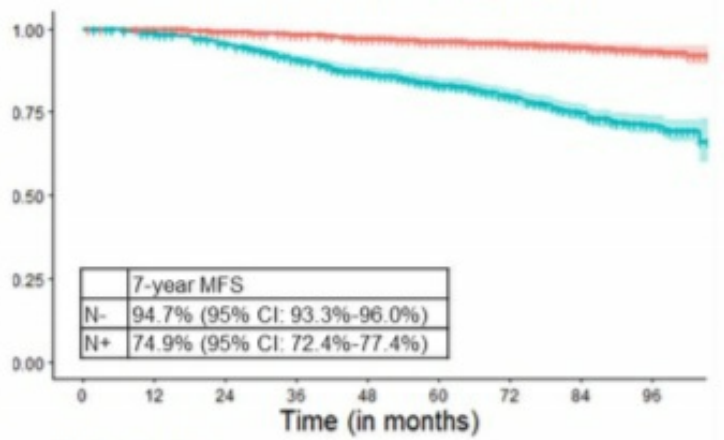

Number at risk

14. $\begin{array}{lllllllll}1176 & 1160 & 1131 & 1096 & 1048 & 986 & 855 & 677 & 268\end{array}$

N. $\begin{array}{lllllllll}1333 & 1304 & 1246 & 1151 & 1057 & 975 & 844 & 637 & 233\end{array}$

D

$=\mathrm{HR}-\mathrm{N}-+\mathrm{HR}-\mathrm{N}+\div \mathrm{HR}+/ \mathrm{N}-+\mathrm{HR}+/ \mathrm{N}+$

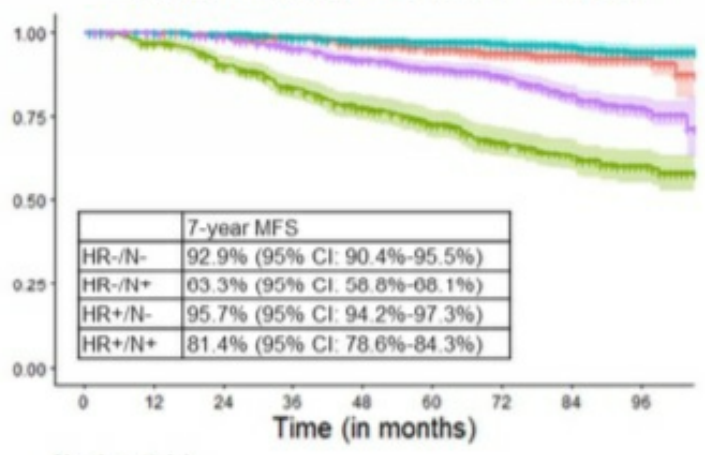

Number at risk

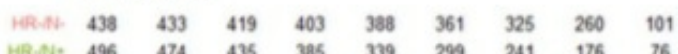

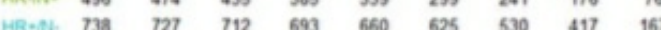

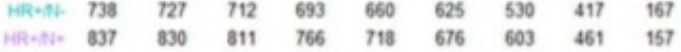

Figure 3

Kaplan-Meier metastatic-free survival curves for subgroups 
A

Overall

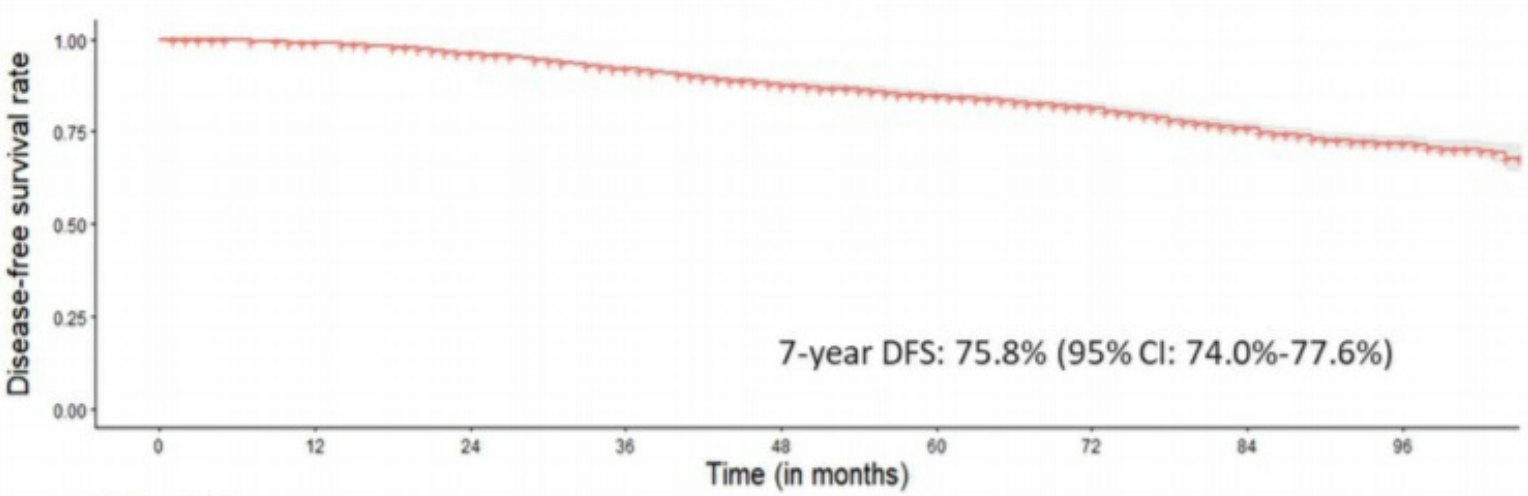

Number at risk

$\begin{array}{llllllllll}\text { ONerail } & 2509 & 2464 & 2377 & 2247 & 2105 & 1961 & 1699 & 1314\end{array}$

B

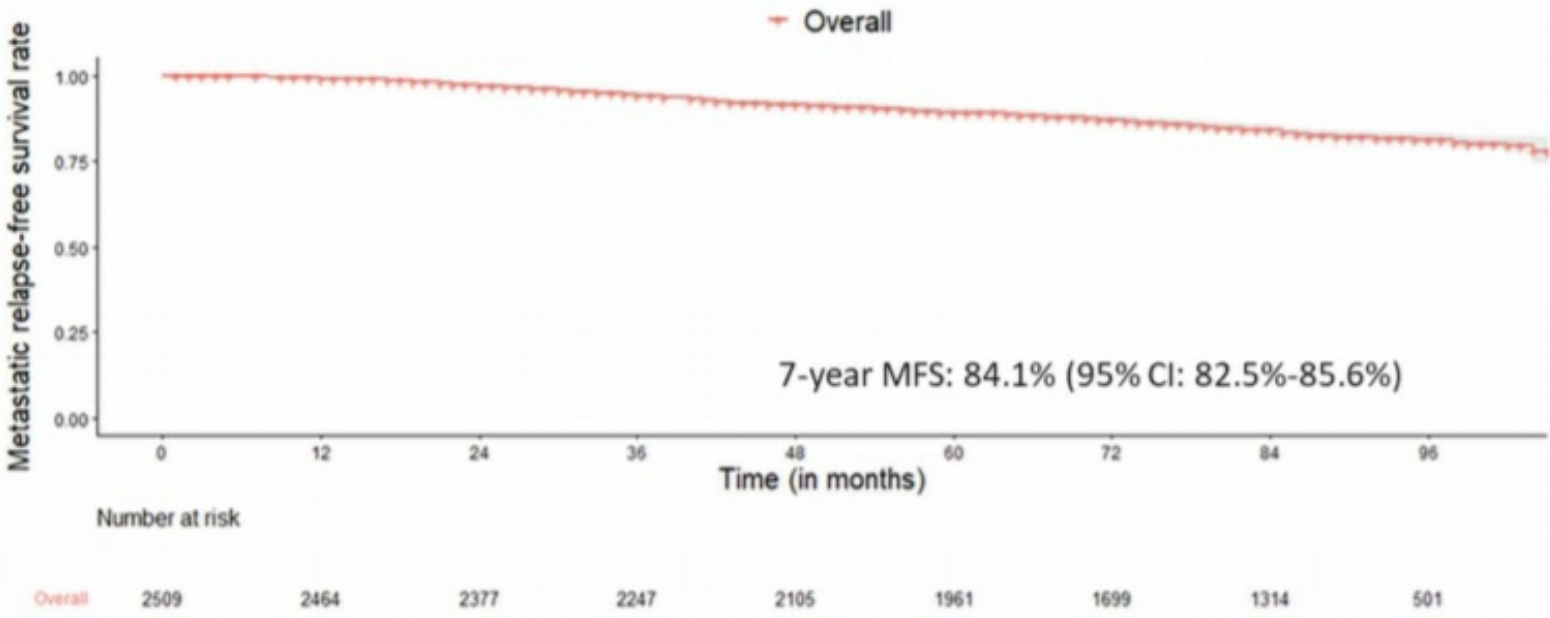

Figure 4

Kaplan-Meier disease-free survival and metastatic-free survival curves (overall population) 